\title{
Médiévales
}

Langues, Textes, Histoire

60 | printemps 2011

La fitna

\section{Une hérésie d'État. Philippe le Bel, le procès des « perfides templiers » et la pontificalisation de la royauté française}

A Heresy of State. Philip the Fair, the Trial of the "Perfidious Templars" and the Pontificalization of French Kingship

\section{Julien Théry}

\section{OpenEdition}

Journals

Édition électronique

URL : https://journals.openedition.org/medievales/6222

DOI : $10.4000 /$ medievales. 6222

ISSN : $1777-5892$

\section{Éditeur}

Presses universitaires de Vincennes

\section{Édition imprimée}

Date de publication : 30 juin 2011

Pagination : 157-185

ISBN : 978-2-84292-273-3

ISSN : 0751-2708

\section{Référence électronique}

Julien Théry, «Une hérésie d'État. Philippe le Bel, le procès des «perfides templiers » et la

pontificalisation de la royauté française », Médiévales [En ligne], 60 I printemps 2011, mis en ligne le 19 janvier 2012, consulté le 22 avril 2022. URL : http://journals.openedition.org/medievales/6222 ; DOI :

https://doi.org/10.4000/medievales.6222 


\section{Julien THÉRY}

\section{UNE HÉRÉSIE D'ÉTAT, PHILIPPE LE BEL, LE PROCÈS DES «PERFIDES TEMPLIERS » ET LA PONTIFICALISATION DE LA ROYAUTÉ FRANÇAISE}

«La politique de Philippe le Bel et de ses ministres peut être définie comme une vaste tentative pour exploiter l'Église au profit de la royauté ${ }^{1}$.»

Il y a, me semble-t-il, deux manières d'aborder l'histoire du célèbre et toujours étrange procès des templiers.

L'une domine depuis toujours. Elle consiste à se demander si les accusés étaient ou non coupables et, le cas échéant, de quoi ils étaient coupables ${ }^{2}$. Avaientils vraiment commis les crimes contre la foi dont ils furent accusés par le roi de France, puis par le pape? L'ordre du Temple était-il hérétique? Ses membres s'étaient-ils seulement laissés aller à des irrégularités, des infractions au droit canonique, bien insuffisantes en elles-mêmes pour justifier la qualification d'hérésie mais grossies, mal interprétées ou instrumentalisées par Philippe le Bel? Dans une telle éventualité, quelles étaient exactement ces infractions? Étaientelles vraiment bénignes? Étaient-elles répandues dans d'autres communautés régulières ou, au contraire, spécifiques au Temple - d'où, peut-être, son destin singulier? Toutes ces questions, même les plus éloignées du point de vue des juges, dérivent des accusations et des événements survenus à l'initiative du Capétien.

L'autre approche - qui sera ici adoptée en fin de compte - est, au contraire, indépendante de toute logique fondée par la procédure. Elle consiste à s'interroger d'abord sur l'attitude de l'unique instigateur du procès, le roi de France. Pourquoi Philippe le Bel et ses principaux conseillers (Guillaume de

1. E. RenAn, «Guillaume de Nogaret», dans Histoire littéraire de la France, t. XXVII, Paris, 1877, p. 298.

2. Cette approche prévaut, par exemple, dans les publications récentes de B. FraLE (voir, entre autres, L'ultima battaglia dei Templari. Dal codice ombra d'obbedienza militare alla costruzione del processo per eresia, Rome, 2001). Cf. aussi, en particulier, J. Riley-Smith, «Were the Templars Guilty?», dans S. J. Ridyard éd., The Medieval Crusade, Woodbridge, 2004, p. 107-124. 
Nogaret et Guillaume de Plaisians, en particulier) firent-ils arrêter et poursuivre les templiers, non seulement à l'encontre des règles du droit canonique, mais aussi à l'insu du pape Clément $\mathrm{V}$ puis, longtemps, contre sa volonté ? Pourquoi ces mesures d'exception? Pourquoi la brutalité, les pressions et les manipulations qui caractérisèrent l'affaire de bout en bout (et en font à juste titre, pour la postérité, le procès politique le plus trouble du Moyen Âge) ? Comment comprendre l'extrême acharnement du Capétien et de son entourage, pendant plus de six ans, à faire reconnaître l' "hérésie» des "perfides templiers» par les accusés eux-mêmes, par les juges ecclésiastiques, par le pape, par tous les habitants du royaume du France et par le concile universel ? Ces questions n'ont pas été clairement posées (chose étonnante, si l'on songe à la fascination exercée par le procès depuis des siècles et à l'accumulation bibliographique afférente).

Selon que l'on donne la priorité à l'un ou l'autre des deux types de questionnement, l'attention ne se concentre pas sur la même catégorie de sources. Dans le premier cas, les procès-verbaux des interrogatoires menés par les juges constituent le principal matériau considéré. En volume, ces aveux et autres dépositions représentent, de loin, le plus gros de la documentation conservée ${ }^{3}$. Ils ont été et sont encore lus, relus et abondamment commentés par les historiens. La seconde approche, en revanche, place au premier plan l'analyse des textes rédigés au nom du roi de France pour lancer, justifier et faire progresser la procédure. Il s'agit entre autres d'articles d'accusation, de lettres au pape, de mandements aux enquêteurs, de convocations aux états généraux réunis pour traiter de l'affaire ou encore de mémoire à usage interne rédigés dans l'entourage royal ${ }^{4}$. Ces documents n'ont guère reçu d'attention. Leur valeur juridique a souvent été mal comprise ou ignorée. On les a jugés trop «idéologiques», trop empreints

3. Principales éditions de ce type de source: L. MénARD, Histoire civile, ecclésiastique et littéraire de la ville de Nismes, t. I, Preuves, Paris, 1744, p. 166-219; Fr. J.-M. RAYNOUARD, Monumens historiques relatifs à la condamnation des chevaliers du Temple, Paris, 1813, réimp. Nîmes, 1999; J. Michelet, Le Procès des templiers, 2 vol., Paris, 1841-1851, rééd. Paris 1987; K. SchotTMüLleR, Der Untergang des Templer-Ordens, mit urkundlichen und kritischen Beiträgen, 2 vol., Berlin, 1887, rééd. 1970, t. II ; H. PRUTZ, Entwicklung und Untergang des Tempelherrenordens, mit Benutzung bisher ungedruckter Materialien, Berlin, 1888, p. 324-364; A. GILMOUR-Bryson, The Trial of the Templars in the Papal State and the Abruzzi, Cité du Vatican, 1982; R. SÈve et A.-M.ChaGnY-Sève, Le Procès des templiers d'Auvergne (1309-1311), Paris, 1987.

4. Principales éditions de ce type de source (la répartition des titres entre cette catégorie et la précédente est évidemment approximative; plusieurs ouvrages contiennent les deux types de document): P. Dupuy, Traittez concernant l'histoire de France, sçavoir la condamnation des Templiers avec quelques actes, l'histoire du schisme, les papes tenans le siege en Avignon et quelques procez criminels, Paris, 1654, p. 78-188; G. Рісот, Documents inédits relatifs aux états généraux et assemblées réunis sous le règne de Philippe le Bel, Paris, 1901, p. 487-720; H. FINKE, Papsttum und Untergang des Templerordens, 2 vol., Münster, 1907, t. II ; G. Lizerand, Le Dossier de l'affaire des Templiers, Paris, 1923. 
de l'exaltation mystique ou de la mauvaise foi des conseillers royaux pour offrir des renseignements utiles. Pris au sérieux, ces textes révèlent pourtant la logique qui présida au procès des templiers. Cette logique était étrangère à l'histoire de l'ordre mais propre, en revanche, à celle de la monarchie capétienne.

Avant de proposer des clefs d'interprétation pour une relecture de l'affaire, j'en retracerai à grands traits la chronologie et reviendrai sur les accusations ${ }^{5}$.

\section{Un bref rappel des faits, de l'arrestation aux derniers bûchers}

Dans un mandement daté du 14 septembre 1307, Philippe le Bel ordonna aux baillis et aux sénéchaux de tout son royaume ainsi qu'à des commissaires spécialement nommés d'entamer des préparatifs secrets en vue d'une arrestation générale des templiers. Cette décision avait pour seule justification et pour unique fondement légal une «mauvaise renommée» (mala fama) qui, depuis quelque temps, imputait aux membres de l'ordre des crimes contre la foi. Les règles de l'enquête criminelle romano-canonique, instituées en premier lieu dans l'Église au début du XIII ${ }^{\mathrm{e}}$ siècle, permettaient l'ouverture d'une procédure judiciaire sans intervention d'un accusateur si un juge supérieur constatait qu'une diffamatio (ou encore infamia) attestait l'existence de faits répréhensibles ${ }^{6}$.

5. La synthèse de référence sur l'histoire du procès demeure celle de M.BARBER, The Trial of the Templars, Cambridge, 1978, nouvelle éd. revue et augmentée Cambridge, 2004. L'exposé qui suit s'appuye principalement sur cet ouvrage sans y faire de renvois systématiques. Voir aussi, entre autres, K. Elm, «Il processo dei templari (1307-1312)», dans F. Tommasi éd., Acri 1291. La fine della presenza degli ordini militari in Terra Santa e i nuovi orientamenti nel XIV secolo, Ponte San Giovanni, 1996, p. 213-225 ; S. Menache, Clement V, Cambridge, 1998, p. 205-246; H. Nicholson, The Knights Templar. A New History, Phoenix Mill, 2001, p. 196-226; A. Demurger, Les Templiers. Une chevalerie chrétienne au Moyen Âge, Paris, 2005, p. 484-509; W.C. JoRDAn, Unceasing Strife, Unending Fear. Jacques de Thérines and the Freedom of the Church in the Age of the Last Capetians, Princeton, 2005, p. 18-32; J. THÉRY, «Procès du Temple», dans N. Bériou et P. Josserand éd., Prier et combattre. Dictionnaire européen des ordres militaires au Moyen Âge, Paris, 2009, p. 743-750. Parmi les études les plus récentes consacrées à certains aspects du procès, signalons P. F. CRAWFORD, «The University of Paris and the Trial of the Templars », dans V. Maillia-Milanes éd., The Military Orders, vol. III. History and Heritage, Aldershot, 2008, p. 115-122; H. Nicholson, The Knights Templar on Trial: The Trial of the Templars in the British Isles, 1308-1311, Stroud, 2009; A. DemuRgER, «'Manuscrit de Chinon'ou 'Moment Chinon'? Quelques remarques sur l'attitude du pape Clément V envers les templiers à l'été 1308 », dans M. Montesano éd., "Come l'orco della fiaba». Studi per Franco Cardini, Florence, 2010, p. 111-121; W.J. CourTENAY et K.UbL, Gelehrte Gutachten und königliche Politik im Templerproze $\beta$, Hanovre, 2010 (MGH, Studien und Texte, 51); enfin les contributions réunies dans J. Burgtorf, P. F. CRAwFord et H. Nicholson, The Debate on the Trial of the Templars (1307-1314), Farnham-Burlington, 2010.

6. W. TRUSEN, «Der Inquisitionsproze $\beta$ : seine historischen Grundlagen und frühen Formen », Zeitschrift der Savigny-Stiftung für Rechtsgeschichte, Kanonistische Abteilung, t. LXXIV, 1988, p. 171-215; R. M. FrAHER, «IV Lateran's Revolution in Criminal Procedure: the Birth of inquisitio, 
La rumeur des crimes commis par les templiers, cependant, n'avait guère été colportée que par le roi de France lui-même et par son entourage - et ce dans un cadre bien précis, celui de négociations difficiles avec Clément V. C'est lors de la première rencontre entre le pape nouvellement élu et Philippe le Bel, à la fin de l'année 1305 à Lyon, que la «mauvaise renommée» des templiers fut évoquée pour la première fois. Auparavant, le Temple avait certes fait l'objet de médisances sporadiques, mais pas plus que d'autres ordres. Ces on-dits n'avaient jusque-là jamais été jugés dignes d'attention de la part d'une autorité judiciaire. Ils n'avaient jamais constitué une diffamatio, c'est-à-dire qu'aucune instance juridictionnelle ne s'était souciée de leur assigner les formes et la valeur légale d'une mala fama susceptible de déclencher des poursuites ${ }^{7}$.

En dénonçant auprès de Clément $\mathrm{V}$ les mauvais bruits qui, prétendument, couraient au sujet de l'ordre - lequel était directement placé sous la juridiction pontificale, puisqu'il bénéficiait de l'exemption -, l'entourage du Capétien avait pour objectif d'exercer sur le pape un surcroît de pression dans un contexte d'âpres discussions dont l'enjeu était tout autre : il s'agissait de s'accorder sur le règlement du conflit qui avait violemment opposé Philippe le Bel et Boniface VIII quelques années plus tôt ${ }^{8}$. L'histoire est bien connue ${ }^{9}$ : en 1302-1303, au plus fort d'une querelle autour des prérogatives de la juridiction pontificale à l'intérieur du royaume de France, le roi avait osé faire déclarer le pape hérétique. Il avait laissé ses conseillers appeler en son nom à la réunion d'un concile universel qui devrait juger et déposer Boniface VIII. Comme on sait, le pape s'apprêtait en réponse à excommunier le Capétien lorsqu'il avait été surpris dans sa résidence d'Anagni et brièvement arrêté par Sciarra Colonna et Guillaume de Nogaret, l'envoyé de Philippe le Bel.

the End of Ordeals and Innocent III's Vision of Ecclesiastical Politics», dans R.J. Castillo LaRA éd., Studia in honorem eminentissimi cardinalis Alphonsi M. Stickler, Rome, 1992, p. 97-111; J. THéry, «Fama: 1'opinion publique comme preuve judiciaire. Aperçu sur la révolution médiévale de l'inquisitoire (XII ${ }^{\mathrm{e}}-\mathrm{XIV}^{\mathrm{e}}$ siècles)», dans B.LemesLe éd., La Preuve en justice de l'Antiquité à nos jours, Rennes, 2003, p. 119-147.

7. Sur le rôle structural des instances judiciaires dans la construction de la «commune voix et renommée», voir J.THÉRY, «Fama...», p. 145-147.

8. G. Lizerand, Clément V et Philippe IV le Bel, Paris, 1910; J. Coste, Boniface VIII en procès. Articles d'accusation et dépositions des témoins (1303-1311), Rome, 1995; S. Menache, Clement V..., p. 191-199.

9. Sur ce célèbre conflit, auquel Pierre Dupuy, au XvII siècle, a donné le nom de «Grand différend», voir entre autres P.Digard, Philippe le Bel et le Saint-Siège de 1285 à 1304, 2 vol., Paris, 1936; J. Coste, Boniface VIII en procès...; A. Paravicini-Bagliani, Boniface VIII. Un pape hérétique?, Paris, 2003; A. BARBERo, «Bonifacio VIII e la casa di Francia», dans Bonifacio VIII. Atti del XXXIX Convegno storico internazionale (Todi 13-16 ottobre 2002), Spolète, 2003, p. 273 327. 
Boniface était mort peu après et son successeur Benoît XI, dont le pontificat dura moins d'un an (d'octobre 1303 à juillet 1304), avait seulement consenti à lever les sanctions canoniques contre le roi. De Clément $\mathrm{V}$, couronné en novembre 1305, Philippe le Bel exigeait non seulement qu'il levât les anathèmes jetés sur les conseillers royaux tenus pour responsables de l'offensive de 13021303 (en particulier Nogaret), mais aussi qu'il ouvrît un procès posthume destiné à prouver l'hérésie de Boniface. La dépouille de ce dernier pourrait alors être exhumée et brûlée, conformément au châtiment prévu pour les hérétiques morts impénitents. L'action naguère conduite par le roi de France contre le pape défaillant serait ainsi reconnue par le Siège apostolique lui-même comme une salutaire entreprise de préservation de la foi.

En 1306-1307, alors que Clément $V$ résistait fermement devant ces prétentions exorbitantes, les accusations de l'entourage royal contre les templiers se firent de plus en plus insistantes. Suite à une nouvelle session de négociations avec le roi tenue à Poitiers au printemps 1307, la rumeur s'amplifia dans des proportions telles que le pape, à la demande des dirigeants du Temple eux-mêmes, envisagea d'ouvrir une procédure judiciaire d'inquisitio veritatis. Le recours à l' «enquête de vérité» paraissait désormais indispensable pour démentir ce que l'on considérait à la Curie comme une mala fama calomnieuse. Avertis par Clément V lui-même de son intention par une lettre du 24 août 1307, le roi et ses conseillers, en réaction, prirent une extraordinaire décision. Ils allaient lancer une procédure royale au plus vite pour devancer l'enquête pontificale - laquelle, une fois déclenchée, leur aurait ôté toute maîtrise de l'affaire.

Le 13 octobre, donc, avec une excellente coordination et à la surprise totale des intéressés, les agents du roi arrêtèrent tous les templiers présents sur le territoire du royaume. Parmi eux figuraient les principaux dirigeants de l'ordre, dont le grand maître Jacques de Molay. Ces dignitaires étaient arrivés récemment de Chypre (où le siège de l'ordre avait été installé depuis la perte de la Terre sainte) pour répondre à une convocation du pape. Clément $\mathrm{V}$ résidait alors en France, retenu depuis son couronnement par les négociations avec le Capétien.

Avec cette arrestation, Philippe le Bel portait une atteinte gravissime et sans précédent aux prérogatives pontificales. Le roi et ses conseillers avaient déjà commis une infraction majeure aux privilèges du for ecclésiastique quelques années plus tôt, en 1301, lorsqu'ils avaient fait saisir la personne de l'évêque de Pamiers, Bernard Saisset, au prétexte que cet ami de Boniface VIII était un traître et un hérétique ${ }^{10}$. Mais ils n'avaient alors soustrait qu'un prélat au monopole de l'Église romaine sur le jugement des membres du haut clergé

10. J. Théry, «Allo scoppio del conflitto tra Filippo il Bello di Francia e Bonifacio VIII: l'affare Saisset (1301). Primi spunti per una rilettura», dans G. Minnucci éd., I poteri universali e 
(ce prélat fût-il, comme Saisset, un champion de la juridiction universelle revendiquée par la papauté). Le 13 octobre 1307, en faisant arrêter l'ensemble des représentants d'un ordre monastique soumis à la seule et unique autorité du Siège apostolique, Philippe le Bel avait pris une initiative non seulement illégale, mais aussi difficilement pensable dans l'ordre du monde tel qu'il était conçu par la majorité des contemporains. Pour faire admettre l'état de nécessité exceptionnelle qui avait imposé cette mesure, il fallait obtenir au plus vite les preuves irréfutables de la réalité et de l'énormité des crimes en cause. Autrement dit, il fallait des aveux. On recourut donc immédiatement à la torture.

Au bout de quelques jours d'interrogatoires, la plupart des dignitaires du Temple reconnurent une partie des faits qui leur étaient imputés. Une telle rapidité fait contraste avec le rythme ordinairement très lent des enquêtes criminelles contre les ecclésiastiques aux XIII et XIV ${ }^{\mathrm{e}}$ siècles ${ }^{11}$. Mais dans le cas présent, grâce à la complaisance de l'inquisiteur de France Guillaume de Paris, lequel était tout dévoué aux intérêts royaux, la juridiction d'Église agissait sous le contrôle direct du roi, de fait sinon de droit ${ }^{12}$. Très vite, dès le 24 octobre, Jacques de Molay confessa que les cérémonies de réception dans l'ordre comportaient un

la fondazione dello Studium Urbis. Il pontefice Bonifacio VIII dalla Unam sanctam allo schiaffo di Anagni, Rome 2008, p. 21-68 [disponible en ligne: http://halshs.archives-ouvertes.fr/].

11. Les enquêtes criminelles de la papauté contre les prélats accusés d' «excès» souvent dits «énormes» furent fréquentes à partir du pontificat d'Innocent III. J'ai étudié le phénomène dans un mémoire de fin de séjour à l'École française de Rome ('Inquisitionis negocia'. Les procédures criminelles de la papauté contre les prélats, d'Innocent III à BenoîtXII (1198-1342). Première approche : aperçu sur les sources de la pratique, juillet 2004; cf. Académie des inscriptions et belleslettres. Comptes rendus des séances de l'année 2004, fasc. 4, Paris, 2006, p. 1617), puis dans un «mémoire original» ( Excès» et «affaires d'enquête». Les procès criminels de la papauté contre les prélats, $X I I I^{e}-m i-X I V^{e} s$.) présenté pour une habilitation à diriger des recherches à l'université de Montpellier III le 23 novembre 2010. Voir aussi J.THÉRY, «Fama ... »; ID., «Justice inquisitoire et construction de la souveraineté : le modèle ecclésial (XII $-\mathrm{XIV}^{\mathrm{e}} \mathrm{s}$.). Normes, pratiques, diffusion », dans Annuaire de l'École des hautes études en sciences sociales. Comptes rendus des cours et conférences 2004-2005, Paris, 2006, p. 593-594; ID., «Faide nobiliaire et justice inquisitoire de la papauté à Sienne au temps des Neuf: les recollectiones d'une enquête de Benoît XII contre l'évêque Donosdeo de'Malavolti (ASV, Collectoriae 61A et 404A)», dans S.Lepsius, T.Wetzstein éd., Als die Welt in die Akten kam. Prozeßschriftgut im europäischen Mittelalter, Francfort, 2008, p. 275-345 [disponible en ligne: http://halshs.archives-ouvertes.fr] ; ID., «Atrocitas/enormitas. Per una storia della categoria di 'crimine enorme'nel Basso Medioevo (XII-XV s.), Quaderni storici, 131, 2009, p. 329-275, repris et développé dans «Atrocitas/enormitas. Pour une histoire de la catégorie d' 'énormité' ou 'crime énorme' au Moyen Âge et à l'époque moderne», Clio@Themis. Revue en ligne d'histoire du droit, 4, 2011, URL: http://www.cliothemis.com/Clio-Themis-numero-4.

12. Guillaume de Paris, au moment de l'affaire du Temple, était aussi le confesseur de Philippe le Bel (après avoir été chapelain royal et confesseur des enfants du roi). Voir S.L. FIELD, The Beguine, the Angel, and the Inquisitor: The Trial of Marguerite Porete and Guiard of Cressonessart, University of Notre-Dame Press, à paraître, chapitre 3 (je remercie l'auteur de m'avoir permis de lire les pages consacrées à Guillaume de Paris avant la parution de l'ouvrage). 
rituel de reniement du Christ. On lui fit immédiatement réitérer sa confession en public, en compagnie d'autres dirigeants eux aussi déjà passés aux aveux. Une déclaration officielle lui fut extorquée, qui fut aussitôt expédiée par le roi aux principaux souverains de la Chrétienté. Molay dut aussi souscrire des lettres adressées à tous les templiers dans lesquelles il leur ordonnait d'avouer. Avant la fin de l'automne 1308, presque tous les prisonniers dont les dépositions nous sont parvenues (cent trente-huit interrogés à Paris, quatre-vingt quatorze en Province) avaient confessé au moins partiellement leur culpabilité.

Pris de court, scandalisé, Clément V s'efforça de reprendre l'affaire en main. Face aux deux cardinaux qu'il envoya à Paris en décembre 1307, certains templiers, dont Jacques de Molay, revinrent sur leurs aveux. Comme Philippe le Bel se refusait en pratique, malgré ses protestations d'intention, à régulariser la situation en remettant les prisonniers à la garde de l’Église, le pape se décida à suspendre de leur office les inquisiteurs du royaume. Le roi avait agi sous leur couvert - ce qui lui permit plus tard de prétendre, non sans impudence, s'être fait l'instrument dévoué de l'Église et même du pontife romain en personne. Avec cette suspense des juges ecclésiastiques, qui intervint en janvier ou février 1308, la procédure était bloquée.

Philippe le Bel réagit par une série de pressions de plus en plus lourdes et directes sur la personne du pape. À la fin du mois de mai 1308, il se rendit à Poitiers, où la Curie résidait. Des négociations s'y poursuivirent pendant plus de deux mois, sous la menace de l'armée royale.L'approbation pontificale de l'action menée contre les templiers constituait désormais la première revendication du roi et de ses conseillers. Mais l'exigence d'un procès contre Boniface VIII était aussi renouvelée avec force. Après quelques semaines de résistance, le pape finit par renoncer à défendre le Temple. Il céda lorsque la possibilité lui fut offerte de préserver ce qui constituait de son point de vue l'essentiel: la suprématie juridictionnelle du Siège apostolique (ne fût-elle que de façade) ${ }^{13}$.

Pour que les procédures reprennent, Philippe le Bel accepta en effet qu'elles soient désormais placées expressément sous l'autorité nominale directe de la papauté. En échange de cette concession toute formelle, dans une série de bulles émises entre le 5 juillet et le 12 août 1308, Clément V reconnut la réalité des crimes déjà avoués par les accusés et lança deux enquêtes. L'une, contre les membres de l'ordre, était confiée localement à l'examen de commissions diocésaines et de conciles provinciaux (sur lesquels le roi, en France, pourrait exercer son contrôle). L'autre enquête, contre l'ordre lui-même, était réservée à des commissions pontificales (celle de France, la plus importante, serait installée à

13. A. Demurger, «'Manuscrit de Chinon'... », donne une interprétation différente de la chronologie. Pour lui, le retournement de Clément $\mathrm{V}$ au détriment des templiers intervint plus tard, en 1309 ou 1310. Il n'y a pas lieu de reprendre ici la discussion sur ce point. 
Paris et composée à la convenance du roi). Un concile général destiné à examiner le résultat des procédures était convoqué pour 1310 à Vienne - non pas, donc, en France comme l'avaient demandé les conseillers royaux, mais, pour transiger, tout près du royaume quoiqu'en terre d'Empire.

Les difficultés rencontrées par les inquisiteurs partout, hormis en France, pour obtenir des aveux contraignirent à repousser la réunion de l'assemblée. Elle s'ouvrit finalement en octobre 1311. Les Pères venus de toute la chrétienté jugèrent très insuffisantes les preuves qui leur furent présentées contre les templiers; seuls les prélats français, soumis à l'influence du roi, furent d'un avis contraire. Clément $\mathrm{V}$, à nouveau placé sous la pression des conseillers et de l'armée du Capétien, fut pourtant contraint de supprimer l'ordre. Afin de ne pas susciter une trop forte opposition de la part du concile, il s'en tint à une mesure purement administrative qui n'était assortie d'aucune condamnation. Trop « diffamé» pour continuer à exister sans scandale, le Temple était dissous «non par sentence judiciaire, mais par provision, en vertu de l'autorité apostolique». Rien n'était décidé quant à la réalité des crimes. Le sort des templiers fut laissé à la décision des conciles provinciaux, exception faite des hauts dignitaires. Ces derniers, après une longue attente, furent abandonnés par Clément $V$ au jugement d'une assemblée ecclésiastique parisienne évidemment placée sous l'emprise royale. Le 14 mars 1314, cette assemblée condamna quatre dirigeants de l'ordre à la prison perpétuelle. Deux d'entre eux, Jacques de Molay et le commandeur de Normandie Geoffroy de Charnay, clamèrent alors leur innocence. Philippe le Bel les fit mourir au bûcher comme relaps le soir même, sans attendre la décision des juges ecclésiastiques.

\section{Offenses au corps du Christ, sodomie, idolâtrie}

Les accusations avancées dans le mandement d'arrestation du 14 septembre 1307 peuvent être regroupées en cinq points.

1) Tout templier, pour être admis dans l'ordre, devait se prêter à un rituel secret. La cérémonie de réception lui imposait, affirmait-on, de renier le Christ à trois reprises en offensant son corps, à chaque fois, par un crachat sur un crucifix. Ce fut là, par la suite, le point d'accusation le plus important.

2) Lors de cette même cérémonie, les nouveaux templiers devaient baiser l'officiant non pas sur la bouche, comme de tradition lors des rituels d'allégeance (pour symboliser l'échange des souffles), mais «au bas de l'épine dorsale». Cet euphémisme désignait un baiser sur l'anus, signe de pacte avec les forces du mal et donc d'entrée en secte démoniaque.

3) Le templier nouvellement reçu était également informé qu'il ne devrait pas refuser de s'adonner à la sodomie avec les membres de l'ordre qui le solliciteraient. Une règle spéciale en la matière (destinée à prémunir les frères 
contre la tentation de forniquer avec des personnes étrangères à la communauté) aurait été inscrite dans les statuts secrets du Temple. Ainsi les accouplements contre nature étaient-ils fréquents parmi les moines-soldats.

4) Les templiers vénéraient une idole.

5) Enfin, les prêtres de l'ordre célébraient la messe sans consacrer l'hostie. On imputait ainsi au Temple, notons-le, une autre manière d'attenter au corps du Christ. Ce dernier était offensé non seulement en sa représentation sur le crucifix, mais aussi sous la forme sacramentelle de l'eucharistie.

La bulle Faciens misericordiam, par laquelle Clément V ouvrit les procédures pontificales contre l'ordre et ses membres en août 1308, était accompagnée de deux listes de 88 et 127 accusations. Dressées par les conseillers de Philippe le Bel, ces listes déclinaient les cinq griefs initiaux en spécifiant un grand nombre de détails scandaleux. Elles n'ajoutaient guère que les trois accusations d'enrichissement illicite (point qui demeura très marginal), d'incroyance à tous les sacrements et d'absolution des péchés, lors des chapitres de l'ordre, par des dignitaires non revêtus de la prêtrise. Seul ce dernier grief reposait sur quelques faits vérifiables. Mais il n'y avait là qu'une mauvaise interprétation du droit canonique (une confusion entre l'absolution des manquements à la règle de l'ordre et l'absolution des péchés). Cette erreur était peu répandue et ne constituait pas un crime contre la foi ${ }^{14}$.

Pour l'essentiel, les accusations reprenaient de vieux stéréotypes sur les hérétiques relayés notamment, en 1233, par la célèbre bulle de Grégoire IX Vox in rama. En 1302 et 1303, Nogaret et Plaisians avaient déjà manié contre Boniface VIII les accusations de sodomie et d'incroyance en l'eucharistie. Le procès posthume du pape Caetani, que les mêmes conseillers royaux parvinrent à faire ouvrir en 1310, vit en outre l'apparition des griefs d'idolâtrie et d'adhésion à une secte hérétique, sans doute par un effet de contamination entre cette affaire et celle du Temple.

Tout au long des quatre années de procès, les templiers de France confirmèrent les accusations de manière plus ou moins exhaustive et circonstanciée dans leurs confessions, selon la dureté des mauvais traitements infligés (auxquels plusieurs dizaines d'accusés succombèrent) et la capacité de résistance de chacun. L'aveu du reniement du Christ lors de l'entrée en religion constituait manifestement l'objectif minimal à atteindre pour les interrogateurs. Ce fut le point d'accusation le plus souvent avoué. Les frères étaient tentés de reconnaître l'existence d'un tel rituel (d'ailleurs avoué par le grand maître) en invoquant la contrainte subie lors de leur réception et en protestant de leur bonne foi personnelle. Ils certifiaient alors avoir renié ore, sed non corde - «par la bouche,

14. J. Riley-Smith, «Were the Templars...», p. 114, surévalue l'importance de cette accusation. 
mais non de cœur»- et pouvaient espérer faire cesser leurs tourments sans s'être trop compromis.

Les procès-verbaux des dépositions sont souvent longs et parfois riches en détails frappants. Ils suscitent la fascination depuis des siècles. Aujourd'hui encore, des historiens travaillent à recouper ces confessions et s'acharnent à en évaluer finement la fiabilité ${ }^{15}$. Il est pourtant illusoire de prétendre y trier le vrai et le faux, puisqu'elles furent produites par une machine judiciaire implacable conçue pour broyer la volonté des accusés ${ }^{16}$. On explore aussi les sources laissées par l'histoire du Temple depuis le début du XII ${ }^{\mathrm{e}}$ siècle dans l'espoir d'y trouver des indices qui puissent confirmer ou expliquer telle ou telle déviance avouée aux inquisiteurs. Ces tentatives pour déceler dans les pratiques réelles de l'ordre des éléments équivoques, susceptibles d'avoir favorisé les accusations royales, ne sont pas convaincantes. Surtout, elles procèdent d'une mauvaise méthode.

De tels efforts débouchent - au mieux - sur des résultats douteux ${ }^{17}$, fatalement impressionnistes et liés à la sensibilité ou à l'humeur de leurs auteurs. Ainsi les conclusions avancées en 2004 par Jonathan Riley-Smith : le «baiser immonde» lors de la réception dans l'ordre aurait bien eu une réalité dans certains cas, mais n'aurait été qu'une mauvaise plaisanterie (horseplay, jocular); l'accusation de vénérer une tête d'idole aurait été liée à la prédilection des templiers pour les reliquaires en forme de tête; l'accusation de sodomie aurait tenu à l'obligation faite à tout templier de partager sa couche pour la nuit avec un confrère de passage si aucun autre lit n'était libre dans la commanderie ${ }^{18} \ldots$ En définitive (et en tout arbitraire), J. Riley-Smith «est enclin à croire que, dans certaines commanderies, des exigences blasphématoires étaient imposées aux postulants au moment de leur réception dans l'ordre ou peu après. Cette pratique existait probablement dans une minorité de commanderies et chez quelques officiants chargés des réceptions en France, mais n'était pas limitée à ces cas ${ }^{19}{ }^{»}$.

15. Ainsi B. Frale a-t-elle mis au point une grande base de donnée recensant tous les aveux documentés et pense avoir ainsi créé un instrument majeur pour éclairer l'histoire du procès (mais il s'agit là d'un cas extrême). Voir B.FRALE, L'ultima battaglia...

16. Voir à ce sujet, en dernier lieu, T.KRÄMER, «Terror, Torture and the Truth: The Testimonies of the Templars Revisited», dans J. Burgtorf, P.F. Crawford et H. Nicholson, The Debate ..., p. 71-85.

17. A. FOREY, «Could Alleged Templar Malpractices have Remained Undetected for Decades?», ibid.,p. 11-19, a récemment esquissé une réfutation des hypothèses en question avec le seul examen de la possibilité (improbable) que les supposées déviances soient passée inaperçues pendant plusieurs décennies avant le procès. Il souligne en outre que les historiens partisans de la thèse des «abus » commis par les templiers, d'un point de vue général, «n'ont pas assez pris en considération les possibles objections à leurs arguments » (p. 19). Mais il est inutile de travailler davantage à élaborer ces objections si, comme je le suggère ici, les hypothèses à réfuter n'ont pas de raison d'être.

18. J. Riley-Smith, «Were the Templars...», p. 113-114.

19. Ibid., p. 124: «[...] inclined to believe that in some commanderies blasphemous demands were being made of postulants at the time of or shortly after their reception into the order. The practice 
Les sacrilèges n'auraient été commis que dans des communautés de France et d'Italie; celles de Germanie, de la Péninsule ibérique (Roussillon inclus) et des îles britanniques, en revanche, étaient clear. Une telle géographie résulte d'une longue analyse probabiliste des dépositions, mais l'auteur ne s'avise pas qu'elle correspond exactement à celle de l'usage de la torture... D' où sa remarque finale selon laquelle «étant données les connaissances actuelles, il est impossible d'établir quand ou pourquoi d'étranges habitudes comme celles-là pourraient s'être insinuées dans un grand et puissant ordre de l'Église ${ }^{20}$ - remarque à laquelle je répliquerai en suggérant plus loin qu'il est possible, en revanche, de comprendre pourquoi ces «étranges habitudes» furent imputées aux templiers par le roi de France. J. Riley-Smith se laisse si bien dominer par la logique procédurale à l'œuvre dans les sources qu'il en arrive même à mettre en doute la validité des rétractations faites par certains accusés au prétexte qu'elles auraient pu être suscitées par d'éventuelles menaces de leurs confrères ${ }^{21}$. Renversement stupéfiant, puisque les confessions rétractées avaient été obtenues précisément et assurément, quant à elles - sous la torture. J. Riley-Smith en arrive finalement à... justifier la torture infligée aux accusés, avec deux arguments ${ }^{22}$. D'abord, le secret prétendument «obsessionnel» cultivé par le Temple (aspect pourtant dépourvu d'une grande spécificité eu égard aux pratiques d'autres ordres) et le serment prêté par les frères à leur entrée les auraient empêchés de parler. En second lieu, le caractère probant des résultats obtenus attesterait l'utilité des tourments: «Les interrogateurs en étaient venus à penser qu'aux scrupules il leur fallait opposer la force si nécessaire; et les déclarations de certains frères semblent leur donner raison ${ }^{23} »$ ! Difficile de ne pas rapprocher ce raisonnement circulaire des efforts pour justifier la torture dans des contextes actuels. La naïveté avec laquelle certains historiens abordent les procédures inquisitoires ne tient pas seulement à une mauvaise connaissance de leur fonctionnement mais aussi, probablement, à une sorte de légitimisme viscéral ${ }^{24}$. Anne Gilmour-Bryson, pour prendre un autre exemple, a récemment consacré un article à la question de savoir si la procédure mise en œuvre contre les templiers était bien adéquate

was probably to be found in a minority of commanderies and among a few receptors in France, but it was not confined to them».

20. Ibid.: «Given present knowledge, it is impossible to establish when or why such odd behavior could have crept into a great and powerful order of the Church.»

21. Ibid., p. 116.

22. Ibid., p. 115-116.

23. Ibid.,p. 115: «Interrogators had come to believe that they had to counteract scrupulousness with force if need be and the statements of some brothers appeared to bear them out.»

24. Voir par exemple, encore, ibid., p. 111-112: «What is striking about the records of many of these inquiries is the serious approach of the investigators.» 
pour faire émerger la vérité des faits ${ }^{25}$. Comme si, sans aucun doute possible, tel avait été son seul et unique objectif.

$\mathrm{Au}$ pire, les recherches centrées sur les procès-verbaux d'interrogatoires pour établir la véracité des crimes aboutissent à des fantaisies demi-savantes. Barbara Frale, sur la base de lectures très personnelles des dépositions, imagine ainsi l'existence d'un mystérieux codice ombra, un manuscrit fantôme qui aurait contenu les règles secrètes de l'Ordre ${ }^{26}$. Récemment, elle a aussi «découvert» que les templiers ont vénéré le fameux «saint suaire» aujourd'hui conservé à $\operatorname{Turin}^{27} \ldots$

La persistance de telles démarches à travers les âges ${ }^{28}$ tient également à la force de vraisemblance inhérente à tout témoignage, jadis décrite par Jeremy Bentham en ces termes: "C'est un fait, et un fait d'expérience criminelle, qu'il y a dans l'homme une tendance à croire au témoignage; et ceci dans n'importe quelle occasion.» Un témoin s'attire toujours, au moins initialement, l'adhésion spontanée de l'auditeur: «Pour croire, pour être justifié de croire, il n'est pas besoin d'une raison spéciale; la confiance est comme acquise d'avance par la vérité du témoignage. Pour ne pas croire, pour être justifié de ne pas croire, il faut une considération déterminée, il faut une raison ${ }^{29}$.»

D'excellentes raisons ne manquent certes pas pour ne pas croire à la véracité des confessions arrachées aux templiers. À mon sens, l'obstination à chercher les traces de réelles irrégularités canoniques révèle combien demeure dérangeante, insupportable peut-être, l'idée que le procès tout entier ne s'est fondé sur rien de vrai. Refus ou impossibilité, donc, sept siècles plus tard, de s'affranchir entièrement de la logique imposée par l'inquisitio veritatis. C'est dire la puissance de cette procédure. Plutôt que d'avoir à reconnaître dans toute sa violence l'arbitraire absolu des institutions d'État lors de l'affaire du Temple,

25. A. Gilmour-Bryson, «The Templar Trials : did the System Work?», The Medieval History Journal, 3/1 (2000), p. 41-65.

26. B. Frale, L'ultima battaglia...

27. EAD., I templari e la sindone di Cristo, Bologne, 2009. Sur ce livre, voir M.VALLERANI, «I templari e la Sindone: 1' 'ipotetica della falsità' e l'invenzione della storia», Historia magistra. Rivista di storia critica, 2 (2009), p. 10-17, et la recension du même sur le site http://www.christianismus.it/. Voir aussi l'article d'A.CARIOTTI, «Sindone: i scritti della discordia», Il corriere della sera (8 janvier 2010), p. 37.

28. Michelet lui-même, à partir de la lecture des dépositions, échaufauda une théorie selon laquelle un rituel de reniement du Christ était bien imposé aux templiers à leur entrée dans l'ordre, mais à la seule fin de tester leur obéissance ou de les préparer à une éventuelle capture par les Sarrasins (théorie qui «ne résiste pas à l'examen», selon les termes d'H.Nicholson, The Knight Templars..., p. 215).

29. J. Bentham, Rationale of judicial evidence, 1827, cité par R. Dulong, Le Témoin oculaire : les conditions sociales de l'attestation personnelle, Paris, 1998, p. 140 et 144 (on trouvera une analyse de l'«énigme fondatrice» du témoignage découverte par Bentham aux p. 139-162). 
les historiens préfèrent souvent illustrer cette figure du déni bien connue des psychanalystes: «Je sais bien, mais quand même ${ }^{30}$.» En dernier recours, une telle attitude tient au refus inconscient de la castration symbolique. Les savants convaincus qu'il ne saurait tout à fait y avoir de fumée sans feu dans l'affaire du Temple cherchent peut-être à préserver, envers et contre tout, une idée rassurante des institutions d'État comme garantes ultimes du juste et/ou du vrai.

Au vrai, tout laisse penser que les templiers étaient innocents - ou plutôt rien, hormis leur arrestation et les aveux forcés, n' autorise à croire qu'ils étaient coupables. Aucun élément de preuve susceptible de corroborer les confessions n'a jamais été découvert. Aucun aveu, autant qu'on sache, ne fut jamais recueilli sans contrainte. Hors de France, les nombreuses procédures menées contre les frères se soldèrent par un échec général ${ }^{31}$ (à quelques exceptions près, en Italie surtout, précisément dans les rares cas où la torture fut employée). Ce contraste entre les résultats abondants dans le royaume capétien et les issues peu probantes ailleurs s'explique bien par le fait que les autres souverains ne partageaient pas les motivations de Philippe le Bel. Les princes de la chrétienté réagirent d'ailleurs avec scepticisme aux lettres envoyées par le roi de France pour les exhorter à agir chez eux. Le seul qui adopta rapidement une attitude défavorable aux templiers, le roi d'Aragon Jacques II, ne porta aucun intérêt à la répression de leurs supposés crimes contre la foi. Pour lui, il y avait là simplement une occasion de prendre le contrôle des biens et des forteresses de l'ordre, nombreux et de grande importance stratégique dans son royaume ${ }^{32}$.

30. O. Mannoni, «Je sais bien, mais quand même», Les Temps modernes, 212 (1964), repris dans ID., Clefs pour l'imaginaire ou l'autre scène, Paris, 1985, p. 9-33. Voir par exemple, là encore, la démarche de J.RiLEY-Smith, «Were the Templars... », p. 116: [Sur les témoignages concernant les actes sacrilèges censés avoir accompagné le rituel de réception] «The evidence they [the witnesses] gave was not consistent and in each case it is hard to tell whether it was true, or invented (or imagined) by the individual concerned, or the product of discussion with other brothers while in prison. Nevertheless a broad pattern emerges » (l'auteur n'envisage pas que ce pattern, c'est-à-dire le modèle ou l'ensemble de constantes dans les témoignages, puisse être tout simplement imposé par l'accusation et par le regard des juges); ou encore p. 117: «Anyone reading the interrogations carefully is left unsure and perplexed, or should be. Nevertheless, I have been struck by the way certain themes run through them and by comments from witnesses which sound so circumstantial that they could hardly have been invented.»

31. Voir, en dernier lieu, H. Nicholson, The Knights Templar on Trial...; J.S. Hamilton, « King Edward II of England and the Templars », dans J.Burgtorf, P. F. Crawford, H. Nicholson, The Debate..., p. 215-224; H. Nicholson, «The Trial of the Templars in Ireland», ibid., p. 225-235; E. Bellomo, «Rinaldo da Concorenzo, Archbishop of Ravenna, and the Trial of the Templars in Northern Italy», ibid., p. 259-272; K. ToOMASPOEG, «The Templars and their Trial in Sicily», ibid., p. 273-283; F. Hooghe, «The Trial of the Templars in the County of Flanders, 1307-12», ibid., p. 285-299.

32. Voir A. Forey, The Fall of the Templars in the Crown of Aragon, Aldershot, 2001. 
Par tous les moyens, y compris les moins légaux et les plus brutaux, Philippe le Bel et ses conseillers empêchèrent les templiers de se défendre. Les hauts dignitaires de l'ordre, quand ils comparurent devant la commission apostolique en novembre 1309 à Paris, trouvèrent Nogaret et Plaisians dans l'assistance. Les deux légistes ne se gênèrent pas pour les menacer ouvertement et les firent ainsi renoncer à plaider leur cause. Au début de l'année 1310, un large mouvement de résistance se fit jour parmi les accusés. Ils furent bientôt près de six cents frères à s'engager pour défendre le Temple devant la commission. Leurs représentants Renaud de Provins et Pierre de Bologne suggérèrent d'abord que Philippe le Bel avait été abusé quand il avait décidé de lancer les accusations. Au moment où la bonne foi du roi commençait à être mise en doute, des mesures radicalement dissuasives bloquèrent net tout développement ultérieur. Le 12 mai 1310, l'archevêque de Sens Philippe de Marigny envoya au bûcher cinquantequatre des templiers défenseurs de l'ordre après les avoir fait juger en hâte. Frère d'Enguerran de Marigny, l'un des principaux conseillers royaux, l'archevêque avait été nommé à son siège à la demande de Philippe le Bel quelques mois plus tôt; c'est dire s'il était une créature du Capétien. Le coup de force du 12 mai était justifié par un raisonnement juridique. Les frères soudainement condamnés avaient naguère fait des aveux devant les commissions diocésaines instituées pour juger les personnes. L'archevêque et ses assesseurs considérèrent qu'en déclarant l'ordre innocent, ces templiers étaient implicitement revenus sur leurs confessions individuelles et pouvaient donc être tenus pour relaps... L'effet recherché fut obtenu. La peur reprit le dessus ; les autres défenseurs se désistèrent en masse. La commission apostolique n'eut plus qu'à poursuivre ses auditions, toutes défavorables au Temple désormais, avant d'envoyer ses procès-verbaux au pape en juin 1311.

L'attitude du Concile de Vienne ${ }^{33}$ confirme aussi l'innocence des templiers, s'il en était besoin. Au vu du résultat des procédures et malgré les efforts déployés par Clément $\mathrm{V}$, les Pères refusèrent de conclure à la culpabilité des accusés. Ils exigèrent qu'une défense du Temple soit organisée. Le pape n'en voulut à aucun prix ${ }^{34}$; l'équilibre auquel il était parvenu dans ses relations avec Philippe le Bel n'y aurait pas résisté. L'issue judiciaire était donc impraticable, d'où le choix de supprimer l'ordre par une décision de type administratif. La bulle Vox in excelso promulgua cette «provision» en la disant approuvée par le Concile. En fait, le pape interdit toute discussion. Une séance plénière se tint à Vienne le 3 avril 1312, en présence du roi de France, pour communiquer aux

33. Sur le déroulement du Concile, le livre de J.Leclerc, Vienne, Paris, 1964 (Histoire des conciles œcuméniques, 8), est particulièrement éclairant.

34. Le pape fit même jeter en prison un groupe de neuf templiers venus inopinément devant le Concile avec l'intention de plaider la cause de l'ordre. 
Pères la teneur du texte. Avant la lecture, un avertissement solennel fut adressé à l'assemblée: quiconque oserait ensuite prendre la parole serait frappé d'une excommunication majeure.

\section{La persécution des templiers et la pontificalisation de la royauté française}

L'interprétation de la chute du Temple la plus claire et la plus synthétique est sans doute celle proposée par Alain Demurger en $2005^{35}$ : en définitive, le Temple semble avoir été un «bouc émissaire» qui a «payé pour tous les ordres militaires internationaux », lesquels «n'avaient pas leur place dans l'État moderne». Avec leurs organisations internes très hiérarchisées et leur soumission directe à la papauté, ces ordres étaient devenus à la fin du XIII siècle «des corps étrangers » dans les royaumes. Ils constituaient « des obstacles au développement des monarchies centralisées ${ }^{36}$. L'analyse est satisfaisante au plan structurel. Mais elle ne rend pas compte des événements dans leur singularité. Pourquoi le Temple? pourquoi Philippe le Bel? Pourquoi un procès en hérésie? Comment expliquer l'initiative inouie de septembre-octobre 1307, l'acharnement des années suivantes?

Rien ne permet de corroborer la vieille hypothèse selon laquelle le principal objectif du roi aurait été de s'approprier les richesses du Temple. L'image de l'ordre s'était certes dégradée avec le recul, puis, en 1291, la perte des dernières positions chrétiennes de Terre sainte: il apparaissait désormais inefficace, mal adapté aux exigences d'une reconquête. Ses activités bancaires pouvaient aussi lui valoir des antipathies. Mais le Temple n'était pas spécialement impopulaire, contrairement à une idée reçue. Par ailleurs, un ancien projet de fusion avec l'ordre de l'Hôpital, déjà évoqué au concile de Lyon II en 1274, avait resurgi peu avant le procès. Philippe le Bel espérait, à l'issue d'une telle réorganisation, faire attacher à la famille capétienne la direction d'un ordre militaire international unique. Les saintes entreprises menées contre les Infidèles par cette nouvelle chevalerie auraient ainsi pu confirmer la mission spéciale impartie à la monarchie française pour la défense de la foi. Or Jacques de Molay, avec une certaine maladresse semble-t-il, s'était opposé à l'intégration des templiers dans un nouvel ordre $^{37}$. Cet élément n'est pas plus décisif que les autres pour la compréhension de l'affaire. Comme les autres, il peut seulement suggérer l'existence de mauvaises

35. A. Demurger, Les Templiers..., p. 484-509.

36. Ibid., p. 499.

37. Voir en particulier A.Demurger, Jacques de Molay: le crépuscule des templiers, Paris, 2002. 
dispositions du roi de France envers le Temple. Malgré des siècles de spéculation, les raisons déterminantes du procès demeurent énigmatiques.

Pour éclaircir ce «mystère d'iniquité»-selon l'expression d'Ernest Renan $^{38}$-, il faut considérer dans son ensemble la crise aiguë survenue dans les rapports entre le roi de France et la papauté à partir de $1301{ }^{39}$. Le conflit prit la forme d'une série de trois procès et culmina, précisément, avec la persécution des templiers. Philippe le Bel bafoua d'abord ouvertement les prérogatives pontificales en faisant arrêter et comparaître devant son conseil l'évêque de Pamiers Bernard Saisset, sur des accusations de haute trahison et d'hérésie montées de toute pièce (le doute n'est pas possible, en tout cas, pour les crimes contre la foi imputés à l'évêque). Provocation grossière: Saisset était le protégé personnel de Boniface VIII et défendait avec intransigeance la supériorité juridictionnelle du Siège apostolique dans le royaume ${ }^{40}$. La violente réaction de Boniface, comme on l'a déjà rappelé, lui valut d'être à son tour accusé d'hérésie, de subir «l'attentat d'Anagni», puis de faire l'objet d'une tentative de procès posthume difficilement enrayée par Clément $\mathrm{V}^{41}$.

À bien des égards, ces trois affaires des années 1301-1314 forment une seule et unique séquence. Entre elles, les similitudes sont très fortes. Même construction, à chaque fois, d'une «mauvaise renommée» pour permettre l'ouverture des procédures royales. Mêmes allégations de l' «énormité» ${ }^{42}$ des crimes et de l'extrême urgence à intervenir pour justifier des violations gravissimes de la juridiction pontificale. Même imitation de la rhétorique pontificale - jusqu'au pastiche - dans les lettres royales. Et, surtout, mêmes efforts exaltés de Nogaret et de Plaisians pour poser Philippe le Bel en garant suprême de la foi, au-dessus du pape.

Au cours de l'affaire Saisset, d'abord, Nogaret avait détourné au profit du roi de France les principaux arguments théologico-juridiques élaborés par la papauté du XIII ${ }^{\mathrm{e}}$ siècle pour revendiquer la «plénitude de puissance»-c'est-àdire la souveraineté absolue. Ces arguments tenaient aux impératifs de la lutte contre l'hérésie. «Vicaire du Christ» ${ }^{43}$, c'est-à-dire son représentant sur terre, le

38. E. Renan, «Guillaume de Nogaret», dans Histoire littéraire de la France, t. XXVII, 1877, p. 291.

39. Voir les références bibliographiques citées supra, note 9 .

40. Sur l'affaire Saisset, voir en particulier J.-M.VIDAL, Bernard Saisset (1232-1311), Toulouse 1926; J.H. Denton, «Bernard Saisset and the Franco-Papal Rift of December 1301 , Revue d'histoire ecclésiastique, 102/2 (2007), p. 399-427; J. THÉRY, «Allo scoppio del conflitto... ».

41. Voir les références bibliographiques citées supra, note 8 .

42. Au sujet de la notion d'enormitas, forgée au XII ${ }^{\text {e }}$ siècle dans la pratique du gouvernement pontifical et utilisée par les juridictions séculières dès le XIII ${ }^{\mathrm{e}}$ siècle, voir J.THÉRY, «Atrocitas/ enormitas...».

43. Voir à ce sujet l'étude classique de M.Maccarone, Vicarius Christi. Storia del titolo papale, Rome, 1952. 
pape poursuivait en effet la mission du Fils de Dieu en préservant la pureté de la foi, condition sine qua non du salut commun ${ }^{44}$. D'où sa supériorité sur tous les pouvoirs terrestres. En accusant Bernard Saisset d'hérésie, Nogaret avait créé l'occasion d'affirmer le droit du Capétien à se substituer au pape, si nécessaire, dans la fonction christique ${ }^{45}$ : désormais, «ce qui [était] commis contre Dieu, contre la foi ou contre l'Église romaine, le roi le considé[rait] commis contre lui». Pour arriver à cette conclusion, formulée au moment où il fallait justifier auprès de Boniface VIII l'arrestation de l'évêque de Pamiers, le légiste avait d'abord cité mot pour mot un passage crucial de la décrétale Vergentis in senium (1199), par laquelle Innocent III avait équiparé l'hérésie au crime de lèse-majesté impériale : «il est plus grave de léser la majesté éternelle que la majesté temporelle». Dans le texte de Nogaret, les effets de cette célèbre formule étaient renversés pour équiparer la juridiction royale à celle du pape, en assimilant implicitement la majesté du Capétien à la majesté divine ${ }^{46}$. Soixante-dix ans plus tôt, les Constitutions de Melfi (1231) avaient fait le même renversement, à partir du même passage de la décrétale Vergentis, au bénéfice de Frédéric II ${ }^{47}$.

Ernst Kantorowicz, dans un célèbre article sur les «mystères de l'État», a parlé de «pontificalisme» pour désigner les fondements religieux de l'absolutisme royal à la fin du Moyen Âge et à l'époque moderne ${ }^{48}$. S'il s'était intéressé de près au cas français et, plus précisément, aux sources judiciaires, administratives et diplomatiques pour l'histoire des conflits entre Philippe le Bel et la papauté, il

44. Sur la théocratie en général et la plenitudo potestatis en particulier, la bibliographie est immense. On se contentera ici de citer le bel article de W.Ullmann, «The Significance of Innocent III's Decretal Vergentis », dans Études de droit canonique dédiées à Gabriel Le Bras, t. III, Paris, 1965, p. 729-741.

45. Démonstration dans J.ThÉRY, «Allo scoppio del conflitto... », en particulier aux p. 51-60. Une version française de cet article, revue et augmentée, est en préparation.

46. «Que [les crimes d'hérésie imputés à Bernard Saisset] gravius longe dictus dominus rex recipit quam superius expressata que contra regiam majestatem commisit dictus episcopus, nec mirum, cum gravius eternam quam temporalem laedere majestatem. Quod insuper in Deum vel fidem vel Romanam Ecclesiam committitur contra se commissum recipit dominus rex predictus, qui et sui progenitores defensores speciales fidei et honoris Romane Ecclesie semper fuerunt» (cité ibid., p. 53, d'après P.Dupuy, Histoire du différend..., p. 629; cf. la nouvelle édition donnée par J.H. Denton, Bernard Saisset..., p. 415-426, à la p. 421).

47. A. Huillard-BréHolles, Historia diplomatica Friderici II, Paris, 1852-1861, t. IV/1, p. 5-7: «Tanto ipsos [les hérétiques] persequamur instantius quanto in evidentiorem injuriam fidei christiane, prope Romanam Ecclesiam [...] superstitionis sue scelera latius exercere noscuntur; immo crimine lese majestatis nostre debet ab omnibus horribilius judicari quod in divine majestatis injuriam dignoscitur attentatum, quamquam in judicii potestate alter alterum non excedat.» Voir à ce sujet E. Kantorowicz, L'Empereur Frédéric II, Paris, 1987 [ed. orig. 1927], en particulier p. 213-224.

48. E. Kantorowicz, «Mystères de l'État. Un concept absolutiste et ses origines médiévales (bas Moyen Âge)» [1955], dans ID., Mourir pour la patrie et autres textes, $2^{e}$ éd., Paris, 2004, p. 93-125, passim. 
aurait pu observer un processus de «pontificalisation» royale extraordinairement explicite ${ }^{49}$. Une deuxième phase s'ouvrit quelques mois après l'affaire Saisset lorsque Plaisians et Nogaret, en accusant Boniface VIII lui-même d'être hérétique, déclarèrent la charge de vicaire du Christ vacante par défaillance de son titulaire. Ils purent ainsi faire endosser à Philippe le Bel le rôle de sauveur de l'Église en le poussant à prendre l'initiative d'un appel au concile universel pour juger Boniface. Dans ses articles d'accusation, Nogaret alla jusqu'à présenter le roi comme un «ange de Dieu », chargé au nom du Ciel de châtier les déviances dans la foi commises par celui qui aurait dû en être l'ultime garant:

Je vous supplie, excellent prince, seigneur Philippe, roi des Francs par la grâce de Dieu, afin que, comme jadis l'ange du Seigneur, l'épée hors du fourreau, s'est mis en travers du chemin [Num 22,31] du prophète Balaam au moment où ce dernier s'avançait pour maudire le peuple du Seigneur, de même vous, qui êtes oint pour l'exécution de la justice et donc en tant qu'ange de Dieu, ministre de la puissance et de votre office, vous vous opposiez, l'épée hors du fourreau, à ce porteur de la peste impie bien pire que ledit Balaam, de sorte qu'il ne puisse mettre à exécution les méfaits contre le peuple dont il a l'intention ${ }^{50}$.

Enfin, la «découverte» par Philippe le Bel d'une «hérésie des Templiers» censée menacer toute la Chrétienté permit d'imposer concrètement l'ascendant du roi au successeur de Boniface VIII. Les textes rédigés à cette occasion par l'entourage royal sont truffés de références bibliques. L'exaltation de la fonction sacrée dévolue au Capétien y est à son comble. La relation directe du roi avec Dieu, sans l'intermédiaire du pape, est affirmée en permanence.

Dans la déclaration de culpabilité que Jacques de Molay fut contraint de souscrire le 25 octobre 1307, par exemple, les conseillers royaux lui firent affirmer que «l'Auteur de la lumière, auquel rien n'est caché» - c'est-à-dire Dieu - venait de révéler les crimes du Temple «par la médiation du ministère du prince très-chrétien le seigneur Philippe ${ }^{51} \gg$. Le roi, dans une lettre envoyée aux prélats

49. Voir à ce sujet J.ThÉRY, «Philippe le Bel, pape en son royaume», L'Histoire, 289 (2004), p. 14-17.

50. J. Coste, Boniface VIII en procès..., p. 115: «Vobis excellentissimo principi, domino Philippo, Dei gratia Francorum regi, supplico, ut, sicut angelus Domini prophete Balaam, antiquitus qui ad maledicendum populo Domini procedebat, occurrit gladio evaginato in via, sic dicto pestifero, qui longe pejor est dicto Balaam, vos qui unctus estis ad executionem justitie, et ideo sicut angelus Dei, minister potestatis et officii vestri, gladio evaginato occurrere velitis, ne possit malum populi perficere quod intendit.» Pour une approche juridique de la mise en accusation du pape, voir T. SснміDT, Der Bonifaz-Prozess. Verfahren der Papstanklage in der Zeit Bonifaz'VIII. und Clemens'V., CologneVienne, 1989.

51. H. Finke, Papsttum und Untergang des Templerordens..., t. II, p. 307-309, à la p. 308 : «Adjiciens insuper verbis lamentabilibus et corde contricto, ut ibidem astantibus videbatur, quod predicta facinora, que propter pene temporalis timorem, et ne destrueretur ordo predictus, in quo 
de France pour les convoquer aux états généraux de 1308, exposait les crimes des templiers en se déclarant lui-même (et sans faire aucune allusion au pape!) «promoteur de cette affaire du Christ, comme il revient à notre majesté ${ }^{52}$ ». Il intimait ainsi aux archevêques, évêques et abbés du royaume l'ordre de le rejoindre à l'assemblée de Tours «au nom du lien de fidélité par lequel vous êtes tenu envers Dieu et envers nous, qui sommes en charge de son intérêt en cette affaire» («qui gerimus ejus negocium in hac parte») ${ }^{53}$. Comment ne pas rapprocher cette formule du «quod in Deum committitur contra se commissum recipit rex » venu sous le calame de Nogaret lors de l'affaire Saisset ${ }^{54}$ ? Devant Clément V, lors d'un consistoire tenu à Poitiers le 29 mai 1308 en présence du roi, Plaisians présenta le Capétien comme le « vicaire temporel du Christ dans son royaume», «choisi par la Providence divine» pour intervenir contre les templiers ${ }^{55}$. Philippe le Bel était déclaré sans ambage «ministre de Dieu», personnellement «tenu de Lui rendre compte de la défense de l'Église ${ }^{56} \gg$. Le 14 juin suivant, dans des

casu amitterent honores mundanos, status et divitias quos habebant, hactenus noluerant revelare, mediante christianissimi principis domini Philippi, Dei gracia Francorum regis illustris, ministerio, lucis Actor, cui nihil est occultum, in lucem deduxit.»

52. G. Рісот, Documents inédits relatifs aux états généraux..., p. 488: «Vobis nichilominus intimantes nos prosecuturos et promoturos negocium Christi predictum, prout ad Christi desideratum obsequium ac ad nostram regiam majestatem dignoscitur pertinere.»

53. Ibid., p. 487-488: «Caritatem vestram in Domino excitantes et nichilominus sub fidelitatis vinculo quo Deo nobisque tenemini, qui gerimus ejus negocium in hac parte, vobis injungentes...»

54. Voir supra, à la note 46.

55. Selon le compte rendu du discours par un témoin aragonais édité dans H.Finke, Papsttum und Untergang..., t. II, p. 142: «Et postquam de hiis locutus est, idem dominus Guillelmus seriose prosecutus est qualiter victoria illa de qua predixit fuit jocunda et mirabilis in progressu propter tria, videlicet propter Dei providentiam eligentem ministrum, propter Dei clementiam providentem magistrum et propter Dei sapientiam ordinantem processum. Dei providentia elegit ad hoc negocium ministrum scilicet regem Francie, qui in regno suo est Dei vicarius in temporalibus, et certo nullus ad hoc magis idoneus inveniri potuisset; nam ipse est princeps devotissimus et christianissimus, potentissimus et ditissimus.»

56. Selon le texte du discours conservé au Trésor des chartes et publié par G.Lizerand, $L e$ Dossier de l'affaire..., p. 126: «Rex catholicus, rex Francorum, non ut accusator, sed ut Dei minister, pugil fidei catholice, leges divine zelator, ad deffensionem ecclesie juxta traditiones patrum sanctorum, de qua tenetur Deo reddere rationem.» Il vaut la peine de placer ici un petit excursus. Quelques mois plus tôt, à l'occasion d'un procès avec l'évêque de Mende pour imposer la juridiction royale sur son temporel (1307), un juriste épiscopal avait répondu aux arguments avancés par l'avocat du roi - qui n'était autre que Guillaume de Plaisians - avec, entre autres, un article rédigé en ces termes: «Item, bien que l'avocat du roi ait allégué que le seigneur roi doit être adoré comme le Seigneur terrestre, nous laissons cela aux hérétiques dont l'hérésie a été condamnée dans le canon Quidam heretici, car nous n'adorons que le Dieu céleste, Créateur des choses du ciel et de la terre» («Item, licet advocatus regius allegaverit dominus regem adorandum esse sicut Dominum terrestrem, hereticis quorum heresio dampnata est in c. Quidam heretici hoc reliquimus, cum Deum celestem, 
circonstances similaires, le même légiste poussa l'audace jusqu'à prétendre que le Christ avait doublement fait «œuvre miraculeuse», d'abord en choisissant un pape français (Clément $V$ était gascon), donc issu du royaume «élu et béni par Dieu au-dessus de tous les autres royaumes du monde», ensuite en faisant résider ce nouveau successeur de Pierre dans le même royaume de France. De cette façon, le Sauveur avait en effet voulu «conjoindre de cœur et de corps» le pape et le Capétien pour que «la puissance de l'un et celle de l'autre, réunies en une seule, combattent pour Lui» contre les templiers ${ }^{57}$. Au même moment, cette volonté d'union forcée s'exprima aussi avec l'exigence capétienne d'une installation définitive de la papauté en France... Étreinte mortelle, en quelque sorte, avec laquelle s'achevait une captation du modèle de souveraineté mystique propre à la théocratie pontificale.

Pour en arriver là, les conseillers royaux avaient donc fait rejouer l'Histoire sainte au détriment des templiers. Comme précedemment au détriment de Boniface VIII (lorsqu'ils avaient invoqué Balaam et l'ange, notamment), ils ajoutaient à cette Histoire un épisode dont le héros était le roi de France. Le reniement du Christ par les templiers, les crachats sur le crucifix et les autres injurie (en particulier le refus de consacrer l'hostie lors de la messe) ${ }^{58}$ n'étaient

Creatorem celestium et terrestrium, tantummodo adoramus » : Mémoire relatif au paréage de 1307, éd. A. Maisonobe, Mende, 1896-1897, t. II, p. 532. Antoine Meissonnier, qui vient d'achever une thèse d'École des chartes consacrée au pariage de Mende en 1307, a eu la gentillesse de me signaler ce passage. Je l'en remercie très vivement). Ce renvoi au Décret de Gratien, C. 24, q. 3, c. 39, (éd. E. Friedberg, Corpus iuris canonici. Pars I. Decretum Gratiani, Leipzig, 1879, c. 1001-1006) ne manquait ni d'insolence, ni d'humour. Le canon Quidam heretici, tiré des Étymologies d'Isidore de Séville, énumérait en une interminable liste toutes les hérésies connues dans l'Antiquité tardive, avec leurs caractéristiques variées. On ignore la teneur exacte des allégations auxquelles le mémoire produit par l'évêque de Mende s'opposait ainsi. L'idée d' "adoration» du roi est assurément une reformulation ironique des prétentions de Plaisians (le verbe «adorer», stigmatisant, était réservé aux hérétiques et ne put donc être employé par le légiste lui-même). On peut toutefois être enclin à croire que le juriste épiscopal exagérait à peine, quand on connaît la tonalité des textes rédigés par les conseillers de Philippe le Bel lors des grandes affaires de 1301-1314. Nul doute, en tout cas, que Plaisians ait laissé libre cours à sa mystique du pouvoir royal dans l'affaire de Mende. L'article du mémoire épiscopal tourne en dérision cette exaltation religieuse de l'autorité capétienne en suggérant - probablement avec un mélange d'humour et d'effarement - qu'il y avait là une déviance assimilable à l'une ou l'autre des hérésies mentionnées dans le plus grand répertoire canonique en la matière.

57. G. Lizerand, Le Dossier de l'affaire..., p. 116: «Christus videtur miraculose egisse ut vos de regno Francie a Domino electo et benedicto pre ceteris regnis mundi apostoli Petri successorem assumpserit vosque in regno predicto presencialiter cum curia vestra in regno predicto adessetis cum rege et ipsum vobis et duos sibi corde et corporali presencia conjunxerit ut utriusque virtus simul unita constanter debellaret pro ipso.»

58. Sur les offenses au Christ via la profanation de l'hostie, voir notamment G.I. LANGMuiR, «The Tortures of the Body of Christ», dans S.L. Waugh et P.D. DienL éd., Christendom and its Discontent. Exclusion, Persecution and Rebellion, 1000-1500, Cambridge, 1996, p. 287-309, et J.-L. SChefer, L'Hostie profanée. Histoire d'une fiction théologique, Paris, 2007. 
en effet rien de moins qu'un renouvellement de la Passion («Dominum nostrum iterum crucifigunt»), au cours duquel le Sauveur subissait des offenses «plus graves que celles reçues sur la croix». Tels sont les termes du mandement d'arrestation ${ }^{59}$ (œuvre de Nogaret) ${ }^{60}$. Et dans son discours du 29 mai 1308 devant Clément $V$ et Philippe le Bel, Plaisians présenta l'initiative royale contre le Temple comme la plus grande victoire remportée par Jésus lui-même depuis sa mort sur la croix ${ }^{61}$. Ce n'est certainement pas un hasard, d'ailleurs, si le mandement fut émis le 14 septembre 1307, précisément le jour de la fête de l'exaltation de la Sainte-Croix. Le choix pour l'arrestation d'un vendredi - jour de la crucifixion - pourrait bien aussi avoir eu un sens religieux.

\section{Destruction du Temple, Nouvelle Alliance et construction du royaume comme corps-Église}

Pourquoi la répression d'une menace hérétique, nécessaire à la transfiguration du roi de France en pontife, s'abattit-elle sur le Temple et pas sur un autre ordre - ou sur tout autre groupe qui pouvait être accusé de former une secte? Outre les faiblesses de l'ordre évoquées plus haut, il y eut sans doute un autre facteur, peut-être déterminant, lié à l'atmosphère eschatologique des premières années du XIV siècle et, plus particulièrement, aux penchants mystiques de Nogaret et de Plaisians. Selon la lettre de convocation des prélats aux états généraux de 1308, la «damnable secte des templiers» avait «la substance de l'Antéchrist » ${ }^{62}$. L'hypothèse d'un sens eschatologique sous-jacent dans l'affaire du Temple exige des recherches approfondies pour être bien étayée. On peut seulement livrer ici quelques pistes.

Selon la littérature prophétique, l'Antéchrist annoncé dans l'Apocalypse de Jean viendrait s'installer dans le Temple de Jérusalem - dont l'ordre des templiers tirait précisément son nom. Des théories de ce genre s'étaient largement diffusées tout au long du XIII ${ }^{\mathrm{e}}$ siècle avec les textes de Joachim de Flore et de ses

59. G. Lizerand, Le Dossier de l'affaire..., p. 18: «Dominum nostrum Jhesum Christum novissimis temporibus pro humani generis redemptione cruxifixum, gravioribus quam in cruce pertulit illatis injuriis, iterum crucifigunt.»

60. Sur Nogaret, Sébastien Nadiras achève actuellement une thèse de doctorat. Voir S. NADIRAS, «Guillaume de Nogaret et la pratique du pouvoir», dans École nationale des Chartes. Positions des thèses, 2003, p. 161-168.

61. Ibid.,p. 111 : «Post illam universalem victoriam quam ipse Dominus Jhesus Christus fecit in ligno Crucis contra hostem antiquum pro defensione ecclesie sue et humani generis redemptione [...] non fecit aliquam particularem victoriam contra inimicos sue ecclesie et fidei orthodoxe, ita miram et magnam et strenuam, ita utilem et necessariam, sicut fecit novissime hiis diebus.»

62. G. Рісот, Documents inédits..., p. 487: «Secta dampnabilis quin pocius ex se ipsa dampnata, vulpium collegium colore religionis opertum, Antechristi tenens substanciam.» 
nombreux imitateurs. Récemment, les écrits d'Arnau de Villeneuve leur avait donné une nouvelle vigueur. Arnau était à Paris en 1300 ; il y défendit son traité De adventu Antichristi devant les théologiens de la Sorbonne ${ }^{63}$. Dès le milieu du $x^{\mathrm{e}}$ siècle, Adson de Montier-en-Der prédisait que l'Antéchrist reconstruirait le Temple. Son Libellus de Antichristo fut d'ailleurs traduit en langue vulgaire à l'initiative des templiers eux-mêmes, tout comme de nombreux autres ouvrages de même nature ${ }^{64}$. Une ambiance eschatologique régnait autour de l'ordre depuis ses origines, au XII ${ }^{\mathrm{e}}$ siècle. Le cistercien Isaac de l'Étoile, violemment opposé à la «nouveauté» qui permettait à des moines de répandre le sang (fût-il celui des Infidèles), avait clairement accusé les templiers de favoriser les desseins cruels du futur «fils de perdition », c'est-à-dire de l'Antéchrist ${ }^{65} \ldots$

Dans certains passages de la Bible, enfin, la destruction du Temple est le préalable à une nouvelle alliance entre Dieu et le peuple élu ${ }^{66}$. Motivations eschatologiques et pontificalisation de la royauté pouvaient donc facilement converger: en faisant rejouer et continuer l'Histoire sainte dans les procès de 1301-1314, la grande affaire de Nogaret et des légistes fut bien de fonder une alliance mystique entre Dieu et son nouveau vicaire en France, le roi capétien. D'autres témoignages subsistent de l'intérêt des conseillers royaux pour cette thématique de l'alliance. Ainsi le préambule d'une lettre d'enquête contre le sénéchal de Carcassonne ${ }^{67}$, rédigée en 1309, qui reprenait - là encore - les termes d'un célèbre texte d'Innocent III, la décrétale Licet Heli (1199) ${ }^{68}$. Au moment de procéder contre un officier corrompu, Philippe le Bel imitait le pape lorsque ce dernier avait sévi, cent dix ans plus tôt, contre un abbé simoniaque ${ }^{69}$ : pour souligner le caractère salutaire de sa démarche, il rappelait le malheur d'Héli. D'après le Livre de Samuel, Dieu avait châtié ce grand prêtre et juge suprême d'Israël, incapable de corriger le mauvais comportement de ses fils et serviteurs, en faisant perdre l'Arche d'alliance aux Hébreux ${ }^{70}$. Déjà en 1308 , lors de son discours du 14 juin devant Clément V, Plaisians avait invoqué la figure d'Héli

63. M. McVAugh, «Arnau de Vilanova and Paris: One Embassy or Two?», Archives d'histoire doctrinale du Moyen Âge, 73 (2006), p. 29-42.

64. S. CeRrINI, La Révolution des templiers. Une histoire perdue du XII siècle, Paris, 2007, p. 236-238.

65. IsaAC de L'Étolle, Sermons, sermon 48 (éd. A. Hoste et G. Raciti, t. III, Paris, 1987 [Sources chrétiennes, 339], p. 158-161). Cf. S. CERRINI, La Révolution des templiers..., p. 44.

66. Cf., notamment, Jer 7, 26-28 et Ez 10, 18 à 11, 23.

67. Éd. E. Cabié et L.MAZEns, Un cartulaire et divers actes des Alamans, Toulouse, 1882, p. 164-165; cf. O. GuyotJEAnNin, «Le roi de France en ses préambules (XI -début du XIV siècle)», Annuaire-bulletin de la Société de l'histoire de France (1998), p. 21-44.

68. Voir à ce sujet J.THÉRY, «Philippe le Bel...».

69. X, 5, 3, 31 (éd. E. FriedBerg, Corpus ius canonici. Pars II. Decretalium collectiones, Leipzig, 1881$, c. $760-761)$.

70. 1 Sam. 2, 12-36, et 1 Sam. 4, 18 . 
pour menacer le pape et lui enjoindre d'abandonner sa politique d'obstruction à la procédure contre le Temple ${ }^{71}$.

Faire reconnaître auprès du pape l'élection divine du Capétien à la fonction suprême de défense de la foi - élection démontrée par la découverte de l'hérésie des templiers en France et non ailleurs, par la victoire sur elle de Philippe le Bel et non d'un autre: un tel enjeu était loin d'être purement théorique. L'affaire du Temple fut décisive pour la transformation du royaume en entité unitaire et autonome sous la forme d'une communauté indissociablement politique et religieuse, cimentée par une foi chrétienne dont le garant était le roi. Une Église royale, donc (en deçà de l'Église gallicane, c'est-à-dire de l'institution ecclésiastique nationale). Ainsi, les premiers vrais états généraux du royaume, convoqués à Tours au début du mois de mai 1308, n'eurent pas pour fonction d'accorder leur consentement à l'impôt (comme ce fut le cas ailleurs en Occident lorsque d'autres princes convoquèrent ce type d'assemblée à partir $\mathrm{du}$ XIII ${ }^{\mathrm{e}}$ siècle) ${ }^{72}$. Si l'on réunit des représentants de tout le royaume à Tours, ce fut uniquement pour les informer du danger hérétique, les faire communier dans l'approbation des actions salutaires de Philippe le Bel et leur faire élire des délégués qui accompagnèrent aussitôt le roi à Poitiers, auprès du pape, pour exiger avec lui la reprise du procès. Déjà en 1302 et 1303, des assemblées avaient été convoquées pour soutenir les accusations contre Boniface VIII. Mais au printemps 1308, l'événement prit des dimensions sans précédent. Outre la noblesse et le clergé, toutes les agglomérations accueillant «foires ou marchés » durent se faire représenter. Plus qu'une opération de propagande ${ }^{73}$, ce fut là un moment d'intense célébration constitutive du royaume comme corps et comme église. Un corps-Église à défendre, sous l'autorité absolue du roi, contre l'ennemi hérétique.

En outre, l'insistance des accusations royales sur les offenses au corps du Christ faites par les templiers n'était peut-être pas sans lien avec un processus

71. G. Lizerand, Le Dossier de l'affaire..., p. 136: «Aliter vicinorum ruent parietes, domus comburentur vosque, quod absit, timere poteritis sentenciam Heli, summi sacerdotis, qui cathedra fractis cervicibus expiravit.»

72. Voir par exemple W. Blockmans, «Representation (Since the Thirteenth Century)», dans C.Allmand éd., The New Cambridge Medieval History, t. VII, Cambridge, 1998, p. 29-64, et J.THéRY, «Moyen Âge» dans P.Perrineau et D. Reynié éd., Dictionnaire du vote, Paris, 2001, p. 667-678 (notamment aux p. 676-677 sur le devenir absolutiste de la monarchie française à partir du règne de Philippe le Bel).

73. A.C. Wilderman, Die Beurteilung des Templerprozesses bis zum 17. Jahrhundert, Fribourg, 1971, p. 26-70; S. Menache, «Contemporary Attitudes Concerning the Templar's Affair: Propaganda Fiasco?», Journal of Medieval History, 8/2 (1982), p. 135-147; EAD., Clement V..., p. 221-222; M. SATORA, «The Social Reception of the Trial and Suppresion of the Templars in Early FourteenthCentury France: The Transmission of Information », dans J. Burgtorf, H. Nicholson, P. Crawford éd., The Debate..., p. 161-168. 
de constitution du royaume de France en corps mystique dont la tête était le roi. L'idée que la société chrétienne tout entière formait un corps mystique dont le Christ et son représentant sur terre, le pape, formaient le «chef» (ou «tête»), habilité à commander à tous les «membres », était assez récente ${ }^{74}$. Boniface VIII et les théologiens de son entourage l'avaient mise en avant autour de 1300 pour justifier les ambitions absolutistes universelles de la papauté. Elle apparaissait en particulier dans la célèbre bulle Unam sanctam (1302), qui proclamait la suprématie du Siège apostolique en réaction aux attaques de Philippe le Bel. $\mathrm{Au}$ cours des procès de 1301-1314, les conseillers royaux commencèrent à capter cette thématique au profit du Capétien. Les premières manifestations d'une conception du royaume de France comme corps mystique ${ }^{75}$ ne sont pas antérieures (contrairement à ce que l'historiographie affirme souvent, à la suite d'E.Kantorowicz, sur la seule base d'une expression de Vincent de Beauvais isolée de son contexte et mal interprétée ${ }^{76}$.

74. Voir en particulier les études classiques d'H. DE LubAc, Corpus mysticum. L'eucharistie et l'Église au Moyen Âge, 2e éd., Paris, 1949, et d'E. Kantorowicz, Les Deux Corps du roi [1957], Paris, 1989, aux p. 145-199. Cf. aussi l'ouvrage récent de G. Briguglia, Il corpo vivente dello Stato. Una metafora politica, Milan, 2006.

75. Conception promise à un grand avenir: elle devint un lieu commun à partir de la seconde moitié du XIv ${ }^{\mathrm{e}}$ siècle. Jean Gerson, par exemple, l'évoque souvent, comme l'a souligné E. Kantorowicz, Les Deux Corps..., p. 162. Cf. aussi J.Krynen, L'Empire du roi. Idées et croyances politiques en France, XIII'-XIV siècle, Paris, 1993 p.242-251.

76. Vincent de Beauvais, Speculum doctrinale [v. 1257], VII, c. 15, éd. Douai, 1624, p. 566. Le corpus rei publice mysticum désigne ici l'ensemble de la chrétienté, sans séparation d'une entité séculière ou, a fortiori, nationale. F. Kantorowicz, Les Deux Corps..., p. 156, cite ce passage d'après une mauvaise référence trouvée chez $\mathrm{O}$. von Gierke et signale d'ailleurs qu'il n'a pas lu le texte. Il se trompe en affirmant que "pour Vincent de Beauvais, l'entité séculière était un 'corps mystique'». Vérification faite, l'encyclopédiste dominicain n'ajoute rien de notable à la traditionnelle conception de la société comme corps, idée organiciste qu'il reprend d'Hélinand de Froidmont (et, à travers ce dernier, de Plutarque et d'Aristote). Vincent ne qualifie le corpus social de mysticum qu'en une occurrence et semble utiliser l'adjectif pour souligner le caractère métaphorique du terme, sans lui donner une dimension religieuse particulièrement marquée (et en aucun cas, par ailleurs, dans une logique de sécularisation ou de nationalisation qui séparerait un corps du royaume de France du reste de la chrétienté et/ou donnerait au Capétien une responsabilité spirituelle supérieure à celle du pape). Le caractère non significatif de cette occurrence est confirmé par l'absence de toute dimension mystique particulière dans la présentation du corpus rei publice qui fait l'objet du premier chapitre du De principi morali institutione, achevé en 1263 par le même Vincent de Beauvais (Vincentii Belvacensis De morali principis institutione, éd. R.J. SCHNEIDER, Turnhout, 1995 ; sur l'ouvrage, voir J.KRYNEN, L'Empire du roi..., p. 173-175). Il n'y a, à ma connaissance, aucun témoignage d'une idée de corpus mysticum regni qui remonterait au XIII siècle en France. Par ailleurs, il me semble probable que Kantorowicz antidate nettement le phénomène de sacralisation des corps politiques (même s'il ne s'agit ici que d'idées partagées par des intellectuels et non de principes mis en œuvre dans des pratiques de gouvernement) lorsqu'il écrit qu' " avant la fin du XIII" siècle, les communautés séculières, grandes et petites, étaient définies comme "corps mystiques" (ID., «Mourir pour la 
Dans l'affaire Saisset, Nogaret avait ainsi présenté l'évêque prétendument hérétique comme un «membre putride», que le Capétien devait «retrancher de son royaume, pour qu'il ne corrompe pas les autres parties du corps $\gg{ }^{77}$. Lors du procès contre le Temple, en revanche, le corps mystique du royaume ne paraît pas avoir été une thématique prégnante. L'idée déterminante pour l'affirmation du corps-église autonome, martelée par les conseillers royaux ${ }^{78}$, était que Dieu avait confirmé, avec l'affaire des templiers, la distinction accordée au royaume de France parmi tous les autres ${ }^{79}$. Ce royaume avait été «spécialement choisi par le Seigneur pour la défense de la foi catholique», comme le disait une lettre de convocation aux états généraux de $1312^{80}$ (réunis à Lyon pour faire pression sur la décision du concile de Vienne).

L'élection du royaume tenait à celle de la famille capétienne ${ }^{81}$. Le processus de sacralisation du pouvoir royal en France a certes commencé très tôt, comme on sait. Les premières traces en remontent au règne de Robert le Pieux, au début du $\mathrm{XI}^{\mathrm{e}}$ siècle. Des étapes importantes furent franchies au temps de Suger, sous Louis VI et Louis VII, puis lors des règnes de Philippe Auguste et de Saint Louis ${ }^{82}$. Il reste à étudier de près les évolutions cruciales qui eurent lieu, à cet égard, au cours du dernier tiers du XIII ${ }^{\mathrm{e}}$ siècle. Les rapports très spéciaux

patrie (Pro patria mori) dans la pensée politique médiévale» [1951], trad. fr. dans ID., Mourir pour la patrie..., p. 127-167, à la p. 155) ou lorsqu'il affirme que l' «équation» entre «corpus reipublicae mysticum, édigé par le Prince», et le «corpus ecclesiae mysticum, édigé par le Christ » était devenue courante «aux alentours du milieu du XIII ${ }^{\mathrm{e}}$ siècle» (ID., «Mystères de l'État... p. 113).

77. Texte cité et commenté dans J.THÉRY, «Allo scoppio del conflitto...», p. 56.

78. Cf., entre autres nombreux exemples, G. Lizerand, Le Dossier de l'affaire..., p. 116: «Vos, de regno Francie a Domino electo et benedicto pre ceteris regnis mundi...»

79. Joseph Strayer a souligné l'importance générale d'une telle idée sous le règne de Philippe le Bel, sans examiner son rôle particulier pour expliquer le procès du Temple. Voir J.R. STRAYER, «France: the Holy Land, the Chosen People, and the Most Christian King», dans T.K. RaBB et J.E. SeIGel éd., Action and Conviction in Early Modern Europe, Princeton, 1969, p. 3-16 (repris dans ID., Medieval Statecraft and the Perspectives of History, Princeton, 1971, p. 300-314).

80. Édition T.HARDY, «Députation des villes du Périgord pour le procès des templiers», Bulletin de la société historique et archéologique du Périgord, 19 (1892), p. 475-483, aux p. 479-480: «Regn[um] Francie, quod pro defensione fidei catholice peculiariter sibi Dominus per sui graciam noscitur elegisse.»

81. Et l'on peut trouver là une confirmation du fait qu'«en France, l'État a créé la nation», comme l'a suggéré B.Guenée, «État et nation en France au Moyen Âge », Revue historique, 237 (1967), p. 17-30, aux p. 27 et 30.

82. M. ВLосн, Les Rois thaumaturges. Essai sur le caractère surnaturel attribué à la puissance royale, particulièrement en France et en Angleterre [1929], Paris, 1983; G. Duby, Le Dimanche de Bouvines, Paris, 1973 ; A.W. LewIs, Le Sang royal. La famille capétienne et l'État. France, $X^{e}-X_{I V}{ }^{e} s$. [1981], trad. fr. Paris, 1986; C. Beaune, Naissance de la nation France, Paris, 1985; J. Le Goff, Saint Louis, Paris, 1996; C. Mercuri, Corona di Cristo, corona di re. La monarchia francese e la corona di spine nel Medioevo, Rome, 2004. 
entretenus par la royauté française avec la théocratie pontificale pendant cette période jouèrent certainement un rôle majeur ${ }^{83}$. Toujours est-il que vers le milieu du règne de Philippe le Bel, au moment du conflit avec le Siège apostolique - et tout particulièrement lors de son dernier acte, l'affaire du Temple-, le phénomène prit la dimension d'une véritable « religion royale ${ }^{84} »$.

Malcolm Barber et A. Demurger - pour ne citer que les plus importants parmi les historiens contemporains du procès - avaient déjà relevé, mais seulement comme des éléments d'explication parmi d'autres, des liens entre l'affaire du Temple et le conflit des années précédentes avec Boniface VIII. Ils n'ont pas manqué de signaler le mysticisme de Philippe le Bel et de ses principaux conseillers, ni de remarquer la nouvelle conception du royaume comme corps dirigé par un roi très-chrétien, vicaire du Christ ${ }^{85}$. William C. Jordan, en étudiant l'expulsion des juifs de France en 1306, a eu l'intuition que la destruction du Temple n'était pas sans lien mystique avec cet événement et faisait même figure de «couronnement de l'action du roi de France comme représentant de la Chrétienté militante ${ }^{86} »$. Mais pour comprendre les causes

83. Pour le suggérer, je me contenterai ici de citer ces paroles adressées par Plaisians à Clément V le 14 juin 1308: «Et certe, pater sancte, non displiceat vobis, plus deconstat Ecclesia Dei regi Francie quam vobis. Nam multi progenitores sui reges Francie fuderunt sanguinem suum pro fide Christi et Ecclesie Dei. Et, ne remota queramus exempla, avus suus sancte memorie sanctus Lodovicus mortuus est prosequendo negocium exaltationis fidei. Rex etiam Philippus, pater istius regis, mortuus est in servitio Ecclesie. Barones etiam et populi istius regni pro Ecclesia Dei fuderunt sanguinem suum. Et in predictorum regum et aliorum sanguine exalta est et radicata Ecclesia Dei et etiam fundata» (éd. H. Finke, Papsttum und Untergang des Templerordens..., t. II, p. 146).

84. Cf., entre autres, J.R. Strayer, «France: the Holy Land... »; J. Le GofF, Histoire de la France. La longue durée de l'État, Paris, 1989, notamment aux p. 141-146; J. KRYNEN, «Rex christianissimus: a Medieval Theme at the Roots of French Absolutism», dans History and Anthropology, 4, 1989, p. 79-96; ID., L'Empire du roi..., p. 345-383 ; E.A.R. BRown, « Kings Like Semi-Gods: The Case of Louis X of France», Majestas, 1 (1993), p. 5-37; ou encore, en dernier lieu, M. KINTZINGER, «Symbolique du sacre, succession royale et participation politique en France au XIV ${ }^{\mathrm{e}}$ siècle», Francia. Forschungen zur westeuropäischen Geschichte, 36 (2009), p. 91-111. L'expression «religion royale» au sens ancien de condition religieuse spécifique du roi (et non de formes «cultuelles » autour de sa personne) est employée par Jean Golein dans son Traité du sacre en 1372 (éd. R.A. JACKson, «The Traité du sacre of Jean Golein», Proceedings of the American Philosophical Society, 113/4 (1969), p. 305-324).

85. M. BARBER, «The World Picture of Philip the Fair», Journal of Medieval History, 8/1 (1982), p. 13-27; A. DemUrger, Les Templiers..., p. 496-497.

86. W.C. Jordan, The French Monarchy and the Jews. From Philip Augustus to the Last Capetians, Philadelphie, 1989, p. 214-215 et n.10 (signalé par A. Demurger, Les Templiers..., p. 499). Le Roman de Fauvel, par exemple, associe l'expulsion des juifs et la destruction de l'ordre du Temple (comme le font beaucoup d'autres textes narratifs de l'époque). L'auteur loue d'ailleurs Philippe le Bel pour son action contre les templiers; il considère que «même saint Louis, en sa gloire, n'avait pas fait aussi bien» et ajoute: «Tres bien en a fait son devoir/Diligaument comme 
déterminantes du procès des Templiers, pour saisir la logique propre qui seule explique les événements dans leur spécificité, il faut placer au premier plan, tout en les reliant, la question des relations du Capétien avec la papauté et celle de la «religion royale». Il faut notamment repérer, dans les textes et dans les procédures, l'appropriation royale des instruments politico-religieux mis au point par la théocratie pontificale ${ }^{87}$.

Le procès du Temple paracheva une œuvre de pontificalisation du Capétien - et donc de construction d'une toute-puissance royale - entrée dans une phase décisive quelques années plus tôt avec l'affaire Saisset, puis avec la mise en accusation de Boniface VIII. La perte des templiers devait faire de Philippe le Bel et de ses successeurs, en quelque sorte, des papes en leur royaume. Lorsqu'au $\mathrm{Xv}^{\mathrm{e}}$ siècle Jean Juvénal des Ursins rappelait à Charles VII qu'il était «vicaire de Dieu en terre ${ }^{88}$ », il ne faisait que reprendre une idée proclamée par Guillaume de Plaisians devant Clément V à Poitiers, en 1308, pour justifier l'action de Philippe le Bel contre les «perfides templiers». En définitive, les crimes imputés au Temple constituaient une hérésie d'État. Leur répression fut un moment important pour la construction de l'absolutisme royal français et, indissociablement, de la «nation France ${ }^{89} »$.

preudomme/Devant l'apoustolle de Romme/A poursui ceste besoigne» (Le Roman de Fauvel, éd. A. LANGFors, Paris, 1914-1919, t. II, v. 999-1002 et 1009-1113 ; cf. J.R. STRAYER, The Reign of Philip the Fair, Princeton, 1980, p. 290-291 et note 158).

87. Si les trois affaires de 1301-1314 furent des moments privilégiés pour l'appropriation du langage et des techniques gouvernementales de la papauté, le phénomène avait toutefois commencé bien avant, sur un mode plus diffus. Pour s'en tenir au seul règne de Philippe le Bel et à un élément très parlant, on peut donner pour exemple l'apparition de références à une plenitudo potestatis du roi dans les documents de chancellerie à partir de 1297, étudiée par J.KRYNEN, «"De nostre certaine science..." Remarques sur l'absolutisme législatif de la monarchie médiévale française», dans A. Gouron et A. Rigaudière éd., Renaissance du pouvoir législatif et genèse de l'État, Montpellier, 1988, p. 131-144. Voir aussi O. Guyotjeannin, «Traces d'influence pontificale dans les actes épiscopaux et royaux français $\left(\mathrm{XIII}^{\mathrm{e}}-\mathrm{XIV}^{\mathrm{e}} \mathrm{s}\right.$.) », dans P.Herde, H. JAKoBs éd., Papsturkunde und europäisches Urkundenwesen: Studien zu ihrer formalen und rechtlichen Kohärenz vom 11. bis 15 Jahrundert, Cologne, 1999, p. 337-364; H.G. SснміDT, «Der Einflu $\beta$ der päpstlichen Justizbriefe auf die Justizbriefe der französischen Königskanzlei um $1300 »$, ibid., p. 365-393.

88. Jean Juvénal des Ursins, Écrits politiques, éd. P. S. Lewis, t. I, Paris, 1978, p. 415-416.

89. Les recherches ici présentées feront l'objet d'un livre à paraître aux éditions Perrin en 2012. Elles ont été entamées en 2006 pour la rédaction de l'article «Procès du Temple», paru dans N. BérIou et P.Josserand éd., Prier et combattre. Dictionnaire européen des ordres militaires au Moyen Âge, Paris, 2009, p. 743-750 (voir aussi «Contre-enquête sur un procès», L'Histoire, 323 (2007), p. 40-47). Elles ont progressé à l'occasion d'interventions au séminaire de Jacques Chiffoleau à l'EHESS (26 avril 2007), au colloque sur L'Età dei processi. Inchieste e condanne tra politica e ideologia nel '300 (Ascoli, Istituto superiori di studi medievali «Cecco d'Ascoli », 30 novembre- 1 $^{\text {er }}$ décembre 2007, organisation Antonio Rigon), au séminaire commun des médiévistes de l'université d'Orléans et de la section de diplomatique de l'IRHT ( $1^{\text {er }}$ février 2008, organisation Jean-Patrice Boudet, Paul Bertrand), et, dernièrement, lors d'une journée d'études sur La Fin de l'ordre du Temple (CEMM, 
Julien ThÉRY - Université de Montpellier III - EA 4207 - CEMM, Route de Mende, F-34199 Montpellier cedex 5

Une hérésie d'État. Philippe le Bel, le procès des «perfides templiers» et la pontificalisation de la royauté française

Après avoir rappelé les grandes lignes de l'affaire du Temple, l'article en esquisse une réinterprétation d'ensemble. L'analyse des sources émises par les instigateurs du procès, le roi de France Philippe le Bel et ses conseillers, est privilégiée. Une logique étrangère à l'histoire de l'ordre mais propre, en revanche, à celle de la monarchie capétienne présida aux événements. La «découverte» et la répression d'une «hérésie des templiers» furent la dernière étape d'un processus, commencé lors du conflit avec Boniface VIII, au cours duquel la royauté française s'appropria les fondements mystiques de la théocratie pontificale. Dans l'affaire du Temple, les légistes royaux achevèrent de sceller une nouvelle alliance entre Dieu et le Capétien. Défenseur suprême de la foi catholique, le roi était désormais investi d'une fonction christique. L'enjeu du procès des templiers fut la transfiguration du pouvoir royal.

Procès des templiers - Philippe le Bel - hérésie - théocratie pontificale - religion royale.

Université Paul-Valéry - Montpellier III, 28 janvier 2011, organisation Marie-Anna Chevalier). Je dois aussi des remerciements à J.Chiffoleau et Yann Potin, stimulants interlocuteurs au fil des années, ainsi qu'à Olivier Mattéoni pour ses remarques très utiles sur une version provisoire de ce texte lors d'une soutenance d'habilitation à diriger des recherches, le 23 novembre 2010 à l'université de Montpellier III. 


\section{A Heresy of State. Philip the Fair, the Trial of the "Perfid Templars" and the Pontificalization of French Kingship}

Having first summed up the Temple case, this article outlines a comprehensive reinterpretation with special regard to the texts written by the instigators of the trial, namely Philip the Fair and his ministers. The logic that prevailed was peculiar to the history of the capetian monarchy; it had nothing to do with the order's history. The «discovery» and repression of the «templars'heresy» was the last step of a process that had begun with the franco-papal rift at the time of Boniface VIII. In this process, the french monarchy appropriated the mystic foundations of the papal theocracy. With the Temple case, the royal legists finished to set the seal on a New Alliance between God and the king. As the ultimate defender of the catholic faith, the capetian king was now fully invested with a christical function. What was at stake in the templars'trial was the transfiguration of the royal power.

Trial of the templars - Philip the Fair - heresy - papal theocracy - royal religion. 
